\title{
HUBUNGAN UKURAN DAN KEMAMPUAN MUAT PERAHU KATIR DI KOTA BITUNG, SULAWESI UTARA
}

\author{
(Relationship between boat dimensions and loading capacity of outrigger boat \\ in Bitung, North Sulawesi) \\ Revols D.Ch. Pamikiran ${ }^{1}$ \\ ${ }^{1}$ Fakultas Perikanan dan Ilmu Kelautan, Universitas Sam Ratulangi, Manado Sulawesi Utara.
}

\begin{abstract}
Perahu katir (pumpboat) di kota Bitung, Sulawesi Utara, digunakan untuk penangkapan tuna dengan menggunakan alat tangkap tuna hand-line. Penelitian ini bertujuan untuk mengetahui hubungan antara ukuran utama perahu dan kapasitas muat (GT). Penelitian ini dilakukan terhadap 92 sampel perahu katir yang tersebar di kota Bitung. Hasil penelitian menunjukkan bahwa hubungan antara ukuran utama perahu katir, Panjang (L) dan Lebar (B), mengikuti persamaan: $B=0,3584+0,0860 \mathrm{~L}$, dengan $\mathrm{r}=0,56$; serta hubungan Panjang (L) dan Dalam (D) mengikuti $\mathrm{D}=0,1491+0,0775 \mathrm{~L}$, dengan $\mathrm{r}=0,64$. Hubungan antara Panjang (L) dan kapasitas muat (GT) perahu katir mengikuti persamaan kuadrat $\mathrm{GT}=0,00887-0,1119(\mathrm{~L})+0,03315(\mathrm{~L} 2)$ dengan $\mathrm{r}=0,72$
\end{abstract}

Kata kunci: katir, pumpboat, tonase kotor.

Outrigger boat (pumpboat) in the city of Bitung, North Sulawesi are used on tuna fisheries using Tuna hand-line fishing gear. The purpose of this research was to determine the relationship between the principle dimension and the loading capacity (GT). This research was conducted on 92, samples of outrigger boats around the city of Bitung. The results showed that the relation between the principle dimensions of outrigger boat was following the equation: $\mathrm{B}=0.3584+0.0860 \mathrm{~L}$, with $\mathrm{r}=0.56$; and $\mathrm{D}=0.1491+0.07 \mathrm{f} \mathrm{L}$, with $\mathrm{r}=0.64$. The relationship between the Length (L) and loading capacity (GT) of outrigger boat was following the quadratic equation that is $\mathrm{GT}=0.00887-0.1119(\mathrm{~L})+0.03315(\mathrm{~L} 2)$ with $\mathrm{r}=0.72$.

Keywords: outrigger, pumpboat, gross tonnage.

\section{PENDAHULUAN}

Jenis-jenis kapal yang sudah umum, digunakan dalam kegiatan penangkapan ikan ini, sekarang kita juga mengenal satu jenis kapal dengan istilah perahu katir (pumpboat). Sebăgai salah satu jenis kapal perikanan, informasi tentang perahu katir ini masih sangat kurang, baik dari segi ukuran, pembuatan dan penggunaannya (Siadadi et al., 2012). Kapal penangkap ikan adalah kapal yang secara khusus dipergunakan untuk menangkap ikan termasuk menapipung, menyimpan, mendinginkan atau mengawetkan. Kapal pengangkut ikan adalah kapal yang secara khusus untuk mengangkut ikan termasuk memuat, menampung menyimpan, mendinginkan atau mengawetkan. Sebagai wahana penampung dan penyimpan hasil tangkapan ikan, maka kemampuan muat kapal menjadi suatu hal yang penting untuk diketahui (Pamikiran, 2010). Kemampuan muat ini berbeda-beda menurut jenis dan ukuran kapal (Panjang/L, Lebar/B, dan Dalam/D). Dalam kaitan dengan register kapal perikanan maka, yang digunakan adalah kemampuan kapal dalam volume kapal dan dikenal dengan istilah Tonase Kotor/Gross Tonnage (GT) dan Tonase Bersih/ Net Tonnage (NT). Ukuran inilah yang digunakan se-
- bagai dasar ukuran kemampuan muat kapal di samping ukuran utama kapal. Penentuan ukuran tonase kapal perikanan dilakukan berdasarkan berbagai aturan, baik secara hukum dan juga secara teknik konstruksi.

Dalam peraturan pemerintah Republik Indonesia No. 51, 2002 tentang perkapalan (DKP RI, 2008), dinyatakan bahwa tonase kapal adalah volume kapal yang dinyatakan dalam tonase kotor (GT) dan tonase bersih (NT). GT merupakan besarnya jumlah volume ruangan tertutup yang dianggap kedap air di dalam kapal ikan. Sedangkan tonase bersih (NT) merupakan isi bersih (Suhariyanto dan Zarochman, 1999).

Dalam Keputusan Presiden No.5 tahun 1989 dinyatakan bahwa pengukuran tonase kapal yang panjangnya $\mathrm{L}<24$ meter mengikuti petunjuk ukur secara nasional dengan rumus yang dinyatakan dalam Suhariyanto dan Zarochman (1999): $\mathrm{GT}=$ volume ruang tertutup $\mathrm{x}$ Register Ton (RT), dimana $\mathrm{RT}=0,353$. Untuk kapal yang berukuran panjang $\mathrm{L} \geq 24$ meter, mengikuti petunjuk pengukuran secara internasional. Dalam Suzuki (1980), dinyatakan bahwa berdasarkan konvensi internasional tentang pengukuran kapal (International Convention on Tonnage Measurement of Ships) 
untuk kapal dengan ukuran panjang $\mathrm{L} \geq 24$ meter, GT dihitung berdasarkan rumus: $\mathrm{GT}=\mathrm{V} . \mathrm{K}$, dimana $\mathrm{V}=$ volume semua ruang tertutup (di atas dan di bawah dek) dalam $\mathrm{m}^{3}$ dan $\mathrm{K}=0,2+0,02 \log 10 \mathrm{~V}$.

Tujuan dari penelitian untuk mengetahui hubungan antara ukuran utama dengan kemampuan muat (GT) pumpboat pada perikanan tuna hand line di kota Bitung, Sulawesi Utara. Penelitian ini diharapkan dapat memberikan informasi sebagai dasar dalam mengestimasi kemampuan muat (GT) berdasarkan ukuran utama pumpboat di kota Bitung.

\section{METODE PENELITIAN}

Penelitian ini dilakukan melalui pencandraan karakteristik teknis kapal sebagai hasil dari pengukuran dan analisis ukuran utama dan kemampuan muat pumpboat dari 92 kapal sampel yang ada di kota Bitung, Sulawesi Utara. Waktu pelaksanaannya dari bulan April-Mei 2012. Objek dari penelitian ini adalah pumpboat pada perikanan tuna hand line di kota Bitung.

Teknik pengambilan data dilakukan melalui pengamatan dan pengukuran terhadap ukuran utama pumpboat sebagai parameter yang akan digunakan dalam menghitung GT, dimana ukuranukuran ini meliputi:

- Panjang (Length/L), panjang seluruh pumpber yang diukur dari bagian ujung buritan hin bagian ujung haluan.

- Lebar (Breath/B), lebar pumpboat yang diukur mulai dari sisi luar kapal yang satu ke sissi lainnya.

- Dalam (Depth/D), dalam atau tingg pumpboat yang diukur mulai dari dek terepdah hingga ke bagian badan perahu terbathatr.

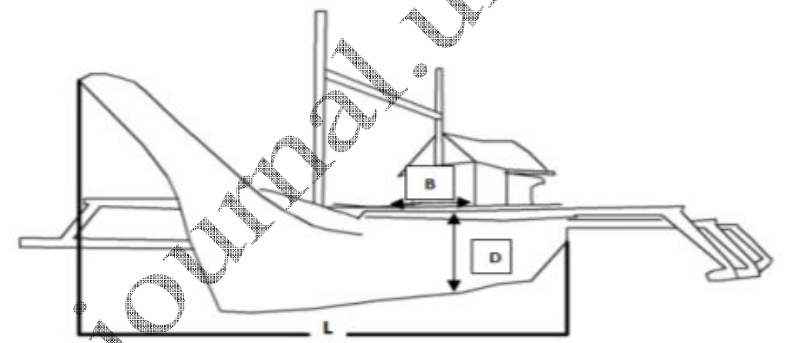

Gaßrary. Pengukuran dimensi utama untuk menghitung GT pada pumpboat.

Figure 1. The principal dimensions measurement for GT calculating on pumpboat.

Untuk menghitung volume ruang tertutup dari pumpboat dilakukan dengan pendekatan koefisien balok (block coefficient/Cb). Mulyono dan Pamungkas (2008) menyatakan bahwa bentuk lambung (hull) pumpboat berbentuk V cenderung memiliki nilai $\mathrm{Cb}$ perahu sebesar 0,5. Perhitungan volume ruang menggunakan rumus yang dikemukakan oleh Fyson (1985) dan telah disesuaikan menjadi:

$$
\mathrm{V}=\mathrm{LxBxDxCb} \text {. }
$$

Untuk kemampuan muat digunakan rumusan yang dikemukakan oleh Suhariyanto dan Zarochman (1999) sebagai berikut:

\section{$\mathrm{GT}=\mathrm{VxRT}=(\mathrm{LxBxDxCb}) \times \mathrm{RT}$}

Analisis hubungan antar ukuran utama $(\mathrm{L}$, B dan D) serta hubungan antara ukuran utama perahu dengan GT dilakukan dengan rumusatmatematis $\mathrm{y}=\mathrm{f}(\mathrm{x})$, dimana $\mathrm{x}$ adalah variable bebas y $\mathrm{ckni}^{-}$ L, y adalah variable tak bebas yakni B. GT. Untuk keperluan analisis dan pe gombaran hubungan antar variabel, digunakan as ikasi CurveExpert 1.40 (Hyams, 2009).

\section{HASIL DAN PEMB GHASAN}

Hubungan antara ukuran utama perahu katir Hasil andlisi dâta terhadap ukuran utama perahu (Tabel $)$ 直emperlihatkan hubungan antara L dan B, sd dara L dan D pumpoat mengikuti pola lineardengan model persamaan matematis sepeng berikut:

B $90,3584+0,0860 \mathrm{~L}$, dengan nilai $r=0,56$. $\mathrm{B}=0,1491+0,0775 \mathrm{~L}$, dengan nilai $\mathrm{r}=0,64$.

emetaan diagram sebaran dan kurva peramalan 'dari kedua hubungan ini disajikan pada Gambar 2 berikut ini.
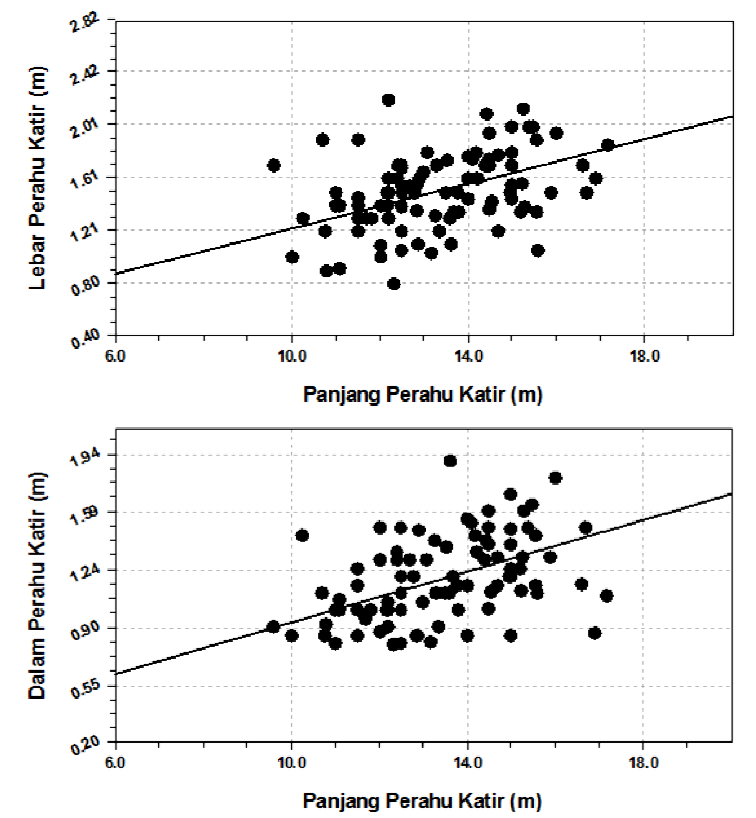

Gambar 2. Hubungan antara Panjang-Lebar dan Panjang-Dalam pumpboat.

Figure 2. Relationship between pumpboat LengthBreath and Length-Depth.

Adanya hubungan antara ukuran $\mathrm{L}$ dan $\mathrm{B}$, serta antara L dan D pumpboat menunjukkan bah- 
wa ada pola bentuk dari pumpboat yang diteliti baik dalam arah $\mathrm{L}, \mathrm{B}$ dan $\mathrm{D}$, sehingga dengan demikian hubungan dalam bentuk persamaan tersebut dapat dipakai sebagai penduga ukuran utama pumpboat.

\section{Hubungan ukuran utama dan kemampuan muat} Analisis data hubungan ukuran utama L dan kemampuan muat (GT) perahu katir dari data pada Tabel 1, adalah sebagai berikut:

$$
\begin{gathered}
\mathrm{GT}_{\text {pumpboat }}=0,00887-0,11197 \mathrm{~L}+0,03315 \mathrm{~L}^{2} \\
\text { dengan } \mathrm{r}=0,72
\end{gathered}
$$

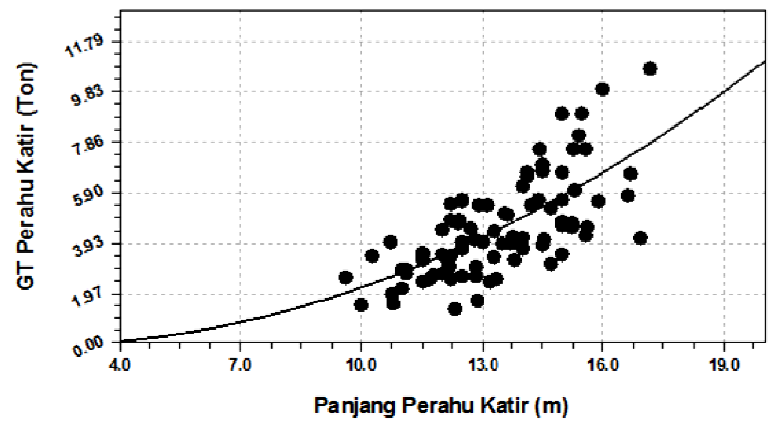

Gambar 3. Hubungan antara Panjang dengan kemampuan muat pumpboat.

Figure 3. Relationship between pumpboat Length and Gross Tonnage.

Hubungan L dan GT pumpboat mengikuti hubungan regresi quadratic fit (Gambar 3), yang artinya pendugaan atau estimasi GT berdasarkan ukuran L pumpboat diperoleh berdasarkan model matematis dengan nilai intercept (b0) dan nilad regresinya (b1 dan b2). Artinya hubungan fividapat digunakan untuk menjelaskan perubahan nilai GT pada setiap perubahan ukuran Qumpost yang disubstitusikan.

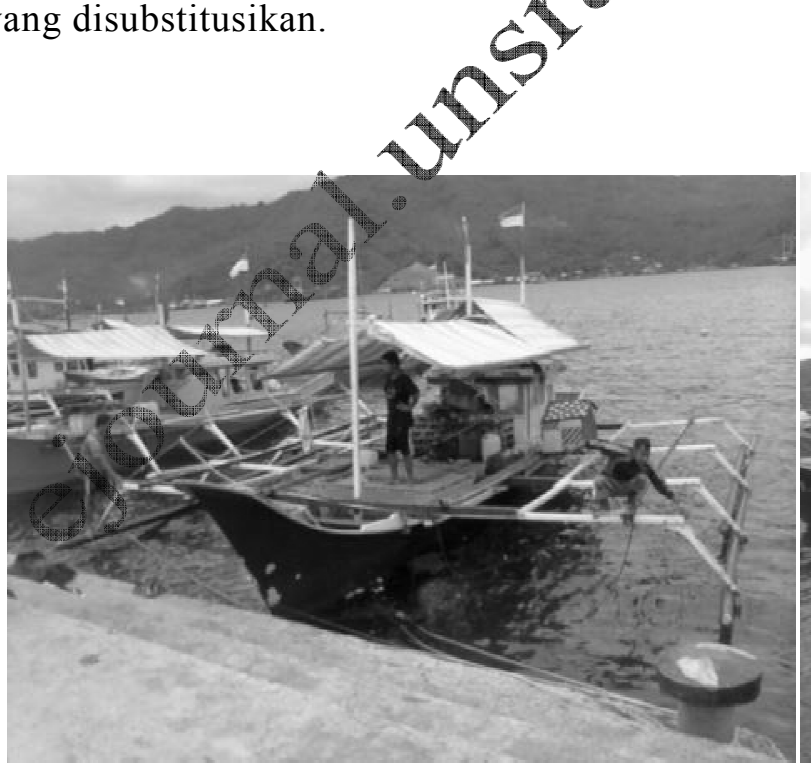

Gambar 4. Sampel perahu katir (pumpboat) di kota Bitung, Sulawesi Utara.

Figure 4. Sample of outrigger boat (pumpboat) at Bitung City, North Sulawesi.

\section{KESIMPULAN}

Pola hubungan antar ukuran utama pumpboat mengikuti model persamaan matematis:

$$
\begin{aligned}
& \mathrm{B}=0,3584+0,0860 \mathrm{~L}, \text { dan } \mathrm{r}=0,56 ; \\
& \mathrm{D}=0,1491+0,0775 \mathrm{~L} \text {, dan } \mathrm{r}=0,64 .
\end{aligned}
$$

Pola hubungan antara ukuran panjang (L) dan kemampuan muat (GT) pumpboat mengikuti model persamaan matematis regresi quadratic fit:

$$
\mathrm{GT}_{\text {pumpboat }}=0,00887-0,11197 \mathrm{~L}+0,03315 \mathrm{~L}^{2}
$$

$$
\text { dengan } \mathrm{r}=0,72 \text {. }
$$

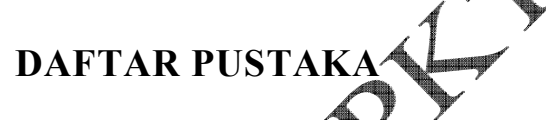

Departemen Kelautan dan Perikananepulik Indonesia. 2008. Himpunan Perundang-undângah Bidang Kelautan dan Perikanan.

Fyson J. 1985. Design of small fishing vessel. Fishing News Books Ltd. England. $80 \mathrm{p}$

Hyams D. 2009. Software Gurve Expert 1.40.

Mulyono dan Pamungkas. 2008. Kajian Teknis Kapal Pumpboat di Bitung fulpwesi Utara. BPIS, Semarang.

Pamikiran RDCK2010. Kajian kemampuan muat kapal perikanan diłtdonesia. Journal Pasific Vol. 2(5): p. 21-28.

Peraturapererintah Republik Indonesia No. 51 Tahun 2002.Tentang Perkapalan.

Siadadi A, Pamikiran RDCh dan Pangalila FPT. 2012. Kajian ukuran utama perahu katir (pumpboat) pada perikanan tuna hand line di Kota Bitung, Propinsi Sulawesi Utara. Jurnal Ilmu dan Teknologi Perikanan tangkap Vol. 1(1): p. $1-5$.

Sohariyanto dan Zarochman. 1999. Hubungan Ukuran Kapal Ikan Daya Penggerak dan Alat Tangkap. Direktorat Jenderal Perikanan Balai Pengembangan Penangkapan Ikan. Semarang.

Suzuki O. 1980. Handbook for Scientists and Technologist, Training Department Southeast Asian Fisheries Development Center.

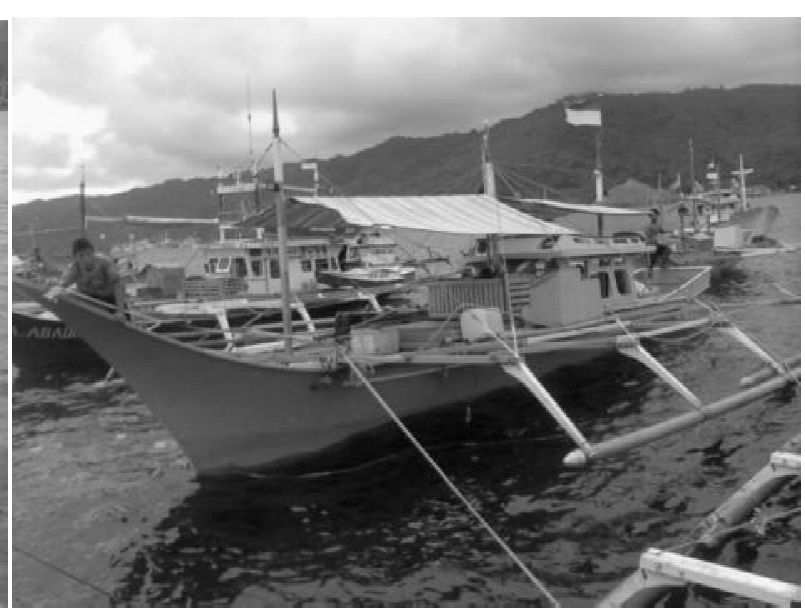


Tabel 1. Hasil pengukuran dimensi utama dan GT perahu katir (pumpboat).

Table 1. measurement results of the main dimensions and GT of the outrigger boat (pumpboat).

\begin{tabular}{|c|c|c|c|c|c|c|c|c|c|}
\hline \multirow{2}{*}{$\begin{array}{l}\text { Nama } \\
\text { Kapal }\end{array}$} & \multicolumn{3}{|c|}{ Ukuran Utama (m) } & \multirow{2}{*}{$\begin{array}{c}\text { GT } \\
\text { (ton) }\end{array}$} & \multirow{2}{*}{$\begin{array}{l}\text { Nama } \\
\text { Kapal }\end{array}$} & \multicolumn{3}{|c|}{ Ukuran Utama (m) } & \multirow{2}{*}{$\begin{array}{c}\text { GT } \\
\text { (ton) }\end{array}$} \\
\hline & Length & Breath & Depth & & & Length & Breath & Depth & \\
\hline KM. Bersama 01 & 9,60 & 1,70 & 0,90 & 2,59 & KM.Sean & 13,30 & 1,70 & 1,10 & 4,39 \\
\hline KM. B Pather & 10,00 & 1,00 & 0,85 & 1,50 & KM. Holliwod 02 & 13,30 & 1,30 & 1,10 & 3,36 \\
\hline KM .Anugerah & 10,25 & 1,30 & 1,45 & 3,41 & KM. Sang Surya & 13,36 & 1,20 & 0,90 & 2,55 \\
\hline KM. Tetesan Berkat & 10,70 & 1,90 & 1,10 & 3,95 & KM. Regina & 13,50 & 1,50 & 1,10 & 3,93 \\
\hline KM. Galuh & 10,75 & 1,20 & 0,85 & 1,94 & KM. Airrella & 13,55 & 1,74 & 1,22 & 5,08 \\
\hline Tidak ada nama & 10,80 & 0,90 & 0,92 & 1,58 & KM. Stewarta 0 & 13,62 & 1,10 & 1,90 & 5,02 \\
\hline KM. Beringin Jaya & 11,00 & 1,50 & 1,00 & 2,91 & KM. Moro seneng & 13,70 & 1,35 & 1,20 & 3,92 \\
\hline KM. Berkat & 11,00 & 1,40 & 0,80 & 2,17 & KM. Samudra Pase & 13,78 & 1,50 & 1,15 & 4,20 \\
\hline KM. Zeboats & 11,10 & 1,40 & 1,00 & 2,74 & KM. Garuda 08 & 13,80 & 1,35 & 1,00 & 3,29 \\
\hline KM. Lukiwan & 11,10 & 0,92 & 1,60 & 2,88 & KM. Virginia & 14,00 & 1,77 & 0,85 & 3,72 \\
\hline KM. Aljon 04 & 11,50 & 1,46 & 1,15 & 3,41 & KM. Putra Bogani & 14,00 & 1,60 & & 6,13 \\
\hline KM.Engel 01 & 11,50 & 1,30 & 1,25 & 3,30 & KM. Rahmat Ilahi & 14,00 & 1,45 & 1,15 & 4,12 \\
\hline KM.Arnava 01 & 11,50 & 1,40 & 1,25 & 3,55 & KM. Tuna Madidir & 14,10 & 1,25 & 1,53 & 6,66 \\
\hline KM.Anugerah 02 & 11,50 & 1,20 & 1,00 & 2,44 & KM. Ditha & 14,10 & 1,8 & 1,45 & 6,50 \\
\hline KM. Lois Star & 11,50 & 1,90 & 0,85 & 3,28 & KM. Sumber Pelita & 14,23 & 160 & 1,35 & 5,43 \\
\hline KM. Bintang Samudra & 11,70 & 1,30 & 0,95 & 2,55 & KM. Arnafat & 14,40 &, 70 & 1,30 & 5,62 \\
\hline KM. Cinta Damai & 11,80 & 1,30 & 1,00 & 2,71 & KM. Sang Surya Star & $14,43^{\circ}$ & 2,10 & 1,42 & 7,59 \\
\hline KM. Angel 03 & 12,00 & 1,90 & 0,87 & 3,50 & KM. Grisia & & 1,37 & 1,10 & 3,86 \\
\hline KM. Alberki & 12,00 & 1,00 & 1,30 & 2,75 & KM. Madidir & 44,50 & 1,75 & 1,50 & 6,72 \\
\hline KM. Tiberias & 12,00 & 1,40 & 1,50 & 4,45 & KM. Abaw 8989 & 14,50 & 1,70 & 1,60 & 6,96 \\
\hline KM. Stelamaris & 12,15 & 1,50 & 1,00 & 3,22 & KM. Hosana 02 & 14,50 & 1,95 & 1,40 & 6,99 \\
\hline KM. 04 JMR & 12,16 & 1,40 & 1,00 & 3,00 & KM.Vanesa 01 & 14,54 & 1,43 & 1,11 & 4,07 \\
\hline KM. Alfa 03 & 12,20 & 1,30 & 0,90 & 2,52 & KM. Imelda & 14,70 & 1,78 & 1,15 & 5,31 \\
\hline KM. Madidir 2 & 12,20 & 1,50 & 1,50 & 4,84 & KM. Jetgilma & 14,70 & 1,20 & 1,00 & 3,11 \\
\hline KM. Fajar & 12,20 & 1,60 & 1,00 & 3,45 & KM, Suńber Pelita & 14,97 & 1,50 & 1,20 & 4,76 \\
\hline KM. Karunia Ilahi & 12,20 & 2,20 & 1,15 & 5,45 & KM. Nuriy & 15,00 & 1,45 & 1,20 & 4,61 \\
\hline KM. Bahtera Iman & 12,30 & 0,80 & 0,79 & 1,37 & KM Untung J.A & 15,00 & 1,70 & 1,49 & 6,71 \\
\hline KM. Alpha Bay & 12,39 & 1,60 & 1,35 & 4,72 & KM. Citra & 15,00 & 1,80 & 1,40 & 6,67 \\
\hline KM. Gracia & 12,40 & 1,70 & 1,30 & 4,84 & KM. Rentangor & 15,00 & 2,00 & 1,70 & 9,00 \\
\hline KM. Mako & 12,49 & 1,68 & 1,50 & 5,56 & KM. Sentosa & 15,00 & 1,70 & 1,25 & 5,63 \\
\hline KM. Niezmar 02 & 12,50 & 1,55 & 1,10 & $3,76^{\circ}$ & KM. Vanesa Star & 15,00 & 1,56 & 0,85 & 3,51 \\
\hline KM. Rajawali 02 & 12,50 & 1,70 & 1,50 & 5,63 & KM. Verqnica & 15,22 & 1,35 & 1,25 & 4,53 \\
\hline KM. JMR 03 & 12,50 & 1,50 & 1,20 & 3,97 & KM. Tulus & 15,24 & 1,57 & 1,12 & 4,73 \\
\hline KM. Kawil & 12,50 & 1,39 & $1,2 \theta$ & 3,68 & Tidak ada nama & 15,27 & 2,14 & 1,32 & 7,61 \\
\hline KM. Rafael & 12,50 & 1,206 & 1,00 & 2,65 & KM. Yuliana & 15,30 & 1,39 & 1,60 & 6,01 \\
\hline KM. Palmas & 12,70 & 1,55 & 1,30 & 4,52 & KM. Tita Qirey & 15,40 & 2,00 & 1,50 & 8,15 \\
\hline KM. Amazing & 12,80 & 5,50 & 1,20 & 4,07 & KM. Mazmur & 15,47 & 2,00 & 1,64 & 8,96 \\
\hline KM. Berkat Samudra & 12,84 & 1,36 & 0,85 & 2,62 & KM. Meltesye 01 & 15,56 & 1,90 & 1,45 & 7,57 \\
\hline KM. Heaven Grace & 12,84 & 1,56 & 0,85 & 3,01 & KM. Maynasye & 15,56 & 1,35 & 1,15 & 4,26 \\
\hline Tidak ada nama & $12,8^{\circ}$ & 1,10 & 0,68 & 1,70 & KM. Sang Surya 04 & 15,60 & 1,50 & 1,10 & 4,54 \\
\hline KM. Jeremaya & 12,90 & 1,60 & 1,48 & 5,39 & KM.Talenta & 15,90 & 1,50 & 1,32 & 5,56 \\
\hline KM. Tanah Merah & & 1,65 & 1,05 & 3,98 & KM. Hosana & 16,00 & 1,95 & 1,80 & 9,91 \\
\hline KM. Singkanaung & 13,10 & 1,80 & 1,30 & 5,41 & KM. Tesa & 16,60 & 1,70 & 1,16 & 5,78 \\
\hline KM. Karunia Ja & 13,10 & 1,80 & 1,30 & 5,41 & KM. Dika Putra & 16,70 & 1,50 & 1,50 & 6,63 \\
\hline KM. Binta & 13,18 & 1,30 & 0,81 & 2,45 & KM. Pandu & 16,92 & 1,60 & 0,86 & 4,11 \\
\hline KM. Jordan 02 & 13,27 & 1,32 & 1,42 & 4,39 & KM. Jenly & 17,18 & 1,86 & 1,90 & 10,72 \\
\hline
\end{tabular}

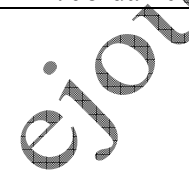

